\title{
Evaluation of Effects of Different Immunosuppressant Agents on Gingival Overgrowth
}

\author{
${ }^{1}$ Ahu Bekit, ${ }^{2}$ Nilsun Bagis, ${ }^{3}$ Nejat Arpak
}

\section{ABSTRACT}

Background: The purpose of this study is to evaluate the effects of different immunosuppressant agents on gingival overgrowth.

Materials and methods: About 60 patients medicated with cyclosporin A (CsA) and 40 patients with tacrolimus (TcR) were recruited in the study. Periodontal examination (PI, GI, PBI, PPD, GO) was carried out only for maxillary and mandibular anterior teeth. Pharmacologic variables, such as daily dosage of immunosuppressant agents, TcR/CsA whole blood level were recorded.

Results: In the group medicated with CsA, 10 patients had clinically significant $\mathrm{GO}$, while none of the patients medicated with Tac had clinically significant GO. Significant differences were observed for periodontal parameters (PI, GI, PBI, PPD), post-transplant period, percentage of GO. In CsA group, significant difference was detected for periodontal parameters, percentage of GO and daily glucocorticoid dosage between responders and nonresponders.

Conclusion: The results from our study show that GO does not occur in patients medicated with TcR, although TcR shares same mechanism with CsA.

Keywords: Cyclosporin-A, Tacrolimus, Gingival overgrowth, Immunosuppressant, Transplantation.

How to cite this article: Bekit A, Bagis N, Arpak N. Evaluation of Effects of Different Immunosuppressant Agents on Gingival Overgrowth. Int J Experiment Dent Sci 2015;4(1):17-22.

Source of support: Nil

Conflict of interest: None

\section{INTRODUCTION}

Renal transplantation is the best therapeutic approach for most subjects with end-stage renal diseases. Immunosuppressive drugs, to prevent the rejection of transplanted

\footnotetext{
${ }^{1,2} \mathrm{PhD},{ }^{3}$ Professor

${ }^{1}$ Department of Periodontology, Bayindir Hospital, Ankara Turkey

${ }^{2}$ Department of Periodontology, Ankara University, Ankara Turkey

${ }^{3}$ Department of Periodontology, Private Practice, Ankara Turkey
}

Corresponding Author: Nilsun Bagis, Assistant Professor Department of Periodontology, Ankara University, Ankara, Turkey Phone: 90-312-2965679, e-mail: nilsunbagis@yahoo.com organs, have increased the success of organ transplant surgeries. ${ }^{1}$ However, a variety of side effects were also observed including nephrotoxicity, ${ }^{2}$ the induction of the diabetic state, neurotoxicity ${ }^{3}$ and gingival overgrowth $(\mathrm{GO})^{2,4-6}$

Gingival overgrowth is characterized by an increase in gingival volume that is usually located in the gingival papillae without extending beyond the mucogingival junction. ${ }^{2,7,8}$ Sometimes, this alteration may extend to the dental crown and interfere in the occlusion, mastication, and phonetics of individuals. ${ }^{6}$

Tacrolimus (TcR) was introduced as an immunosuppressive agent for organ transplants in 1987 and may be an excellent alternative to cyclosporin A (CsA). ${ }^{7}$ Tacrolimus has similar side effects compared to those of CsA, but, when GO is concerned, the results appear to differ. Some studies associated the occurrence of GO with the use of $\mathrm{TcR}^{8}{ }^{8}$ although at less frequency than with $\mathrm{CsA} .{ }^{7,9} \mathrm{In}$ contrast, other studies ${ }^{5,6}$ suggested that TcR is not associated with GO. The prevalence of GO induced by CsA ranges from 20 to $35 \%$, and the high incidence could be related to the concomitant use of calcium channel blockers. ${ }^{10-12}$ The prevalence of GO induced by TcR is $\sim 14 \%$, ${ }^{6,10}$ and the concomitant use of calcium channel blockers also leads to an increase in the severity of this condition. ${ }^{6,7}$

The aim of this longitudinal study is to compare the incidence and severity of GO associated with the administration of immunosuppressive drugs, such as CsA and $\mathrm{TcR}$, absence of calcium channel blockers in patients who underwent renal transplantation (RT) and to investigate the effects of potential risk variables associated with GO on these groups of subjects.

\section{MATERIALS AND METHODS}

\section{Study Population}

A hundred of patients with renal transplantation ( 38 females and 62 males) and at least 3 months postrenal transplant period under an immunosuppressive therapy based on CsA or TcR (CsA group $n=60, T c R$ group $n=40)$ were recruited. Patients' years of age were $36.19 \pm 10.09$ [mean \pm standard deviation (SD)]. A study was conducted at the Ankara Etlik Ihtisas Hospital's Transplantation Clinic and Başkent University Transplantation Clinic between 2004 and 2006. The study was approved by 
the Ethical Committee for the use of human subjects in research, Ankara University, Faculty of Dentistry (No. 75, on Dec 9, 2004).

All subjects in this study of both sex $\geq 18$ years. The following inclusion criteria were adopted: (1) At least 3 months postrenal transplant period under an immunosuppressive therapy, (2) a minimum of six of the 12 most anterior teeth in the upper or lower dental arches. Exclusion criteria were as follows: (1) Smokers and/ or patients with diabetes, pregnancy, lactation period. (2) Patients who used drugs, such as calcium canal blockers, phenytoin, sodium valproate and medicated antibiotics, such as azithromycin 3 months before the examination. (3) Patients who had a nonsurgical periodontal treatment during the previous 6 months; surgical periodontal treatment over the previous 12 months.

\section{Medical and Pharmacological Variables}

Medical and pharmacological data were obtained from each subject's medical records. As part of long-term management, transplant recipients were screened regularly for whole blood and serum concentrations of the main immunosuppressive agent. Data from the most recent assessment, usually on the last medical examination (0-30 days, range of time between medical exam and study visit), were recorded. Gender, age, body weight, donor type, time since transplant, main immunosuppressive agent dosage and serum level, creatinine level as well as the use of prednisone, azathioprine, and mycophenolate mofetil (MMF) were used in the analysis. Patients' medical records were thoroughly examined and data were confirmed (or updated when pertinent) by the organ transplant medical group.

\section{Clinical Parameters assessed}

After the examination of patients' medical records and after applying exclusion and inclusion criterion, subjects were scheduled for gingival evaluation. Gingival evaluation was performed by a single-trained and calibrated examiner (AA) who was blinded to each patient's identity, medical history, and immunosuppressive regimen. Examiner calibration was performed at the beginning of the study and repeated 1 month later to determine intraexaminer reliability. For this purpose, papillary bleeding index (PBI) and GO scores of 10 subjects were evaluated. All nonweighted $k$ scores were $>0.92$ and intra-class correlation coefficients were $>0.90$.

Clinical parameters were measured with a millimetergraded manual periodontal probe $^{\dagger}$ in six of the most anterior teeth $^{13,14}$ in the dental arch and at four sites per tooth (distal, mid-buccal, mesial, mid-lingual). The following clinical parameters were determined: Probing pocket depth (PPD), the PBI of Saxer Mühlemann, ${ }^{15}$ the plaque index (PI) of Silness and Loe, ${ }^{16}$ the gingival index (GI) of Löe Sillness ${ }^{17}$ and GO. The gingival overgrowth index (GOI) was adapted from Seymour et $\mathrm{al}^{18}$ and was recorded in the vestibular, palatine, and lingual papillae of the teeth of each individual. Each papilla received a score that ranged between 0 and 5, depending on the degree of overgrowth in both the horizontal and vertical axes. Therefore, a total of 20 papillae (10 maxillary and 10 mandibular papillae) were examined in each patient, and the maximum score that each individual could reach was 100, allowing the value found in each individual to be expressed as a percentage. Subjects with GO scores $\geq 30$ were classified as having clinically significant overgrowth as suggested previously. ${ }^{10}$

\section{STATISTICAL ANALYSES}

Individual patient data, including demographic, pharmacological and periodontal variables, were collected and transcribed into a statistical database. ${ }^{\ddagger}$ The comparison of variables among the groups was performed using the unpaired independent sample $t, \chi^{2}$ statistic, or MannWhitney tests, as appropriate. Statistical data analysis accounted for sample size differences of the two groups. Data were initially examined using univariate regression analyzes to evaluate the effect of each independent variable on the prevalence and severity of GO, in both TcR and CsA groups. The effects of the variables on the GO scores were subsequently examined using both backward and forward stepwise regression analyzes and the general linear model. The regression coefficients, their $95 \%$ confidence interval (CI), and p-values were also reported.

\section{RESULTS}

The characteristics of the immunosuppressive groups, in relation to the presence and severity of GO, are shown in Table 1. Ten subjects were classified as presenting clinically significant GO (scores $\geq 30 \%$ ). All of these subjects were in CsA group.

Table 1: The characteristics of the immunosuppressive groups, in relation to the presence and severity of GO

\begin{tabular}{lllllll}
\hline & \multicolumn{3}{c}{ CSA } & & \multicolumn{2}{c}{ TCR } \\
\cline { 2 - 3 } \cline { 6 - 7 } Clinically significant GO & $n$ & $\%$ & & & $\%$ \\
\hline Absence & 50 & 83.3 & & 40 & 100 \\
Presence & 10 & 16.7 & & 0 & 0 \\
\hline Total & 60 & 100 & & 40 & 100 \\
\hline
\end{tabular}

GO: Gingival overgrowth

†PCP-UNC 15, Hu-Friedy, Chicago, FL; ${ }^{\ddagger}$ Statistical Package for Social Sciences, Version 10.0 for Windows, SPSS, Chicago, IL 
Evaluation of Effects of Different Immunosuppressant Agents on Gingival Overgrowth

Table 2: Demographic, pharmacological and periodontal variables of subjects

\begin{tabular}{|c|c|c|c|c|c|c|c|c|c|}
\hline & \multicolumn{4}{|c|}{$T c R$} & \multicolumn{4}{|c|}{ CsA } & \multirow[b]{2}{*}{$p$-value } \\
\hline & Mean & $S D$ & Min. & Max. & Mean & $S D$ & Min. & Max. & \\
\hline Age & 31.85 & 8.85 & 18 & 47 & 39.08 & 9.90 & 20 & 68 & $<0.001$ \\
\hline Weight (kg) & 64.37 & 13.15 & 32 & 94 & 69.21 & 13.03 & 44 & 98 & NS \\
\hline Months of after RT & 32.30 & 30.34 & 3 & 140 & 74.93 & 38.15 & 18 & 221 & $<0.001$ \\
\hline Serum creatinine concentration $(\mathrm{mg} / \mathrm{dl})$ & 1.33 & 0.38 & 0.70 & 2.30 & 1.39 & 0.49 & 0.60 & 2.90 & NS \\
\hline $\mathrm{PI}$ & 0.98 & 0.63 & 0.22 & 2.35 & 1.33 & 0.77 & 0.10 & 3.00 & $<0.05$ \\
\hline GI & 0.47 & 0.38 & 0.10 & 1.43 & 1.87 & 0.68 & 0.11 & 3.00 & $<0.001$ \\
\hline PPD & 2.10 & 0.51 & 1.35 & 4.02 & 2.51 & 0.93 & 0.22 & 5.18 & $<0.05$ \\
\hline PBI & 0.36 & 0.31 & 0.00 & 1.50 & 0.62 & 0.63 & 0.00 & 3.00 & $<0.05$ \\
\hline Daily dosage of TcR (mg/day) & 4.55 & 2.37 & 1 & 13 & - & - & - & - & - \\
\hline Daily dosage of CsA (mg/day) & - & - & - & - & 145.83 & 41.21 & 50 & 225 & - \\
\hline Daily dosage of glucocorticoid (mg/day) & 5.82 & 1.87 & 4.00 & 10.00 & 5.69 & 1.79 & 4.00 & 15.00 & NS \\
\hline Blood TcR level (ng/ml) & 7.69 & 2.96 & 4.3 & 22.9 & - & - & - & - & - \\
\hline Blood CsA level (ng/ml) & - & - & - & - & 636.75 & 137 & 258 & 952 & - \\
\hline $\mathrm{GO}(\%)$ & 2.55 & 4.67 & 0.00 & 15 & 12.36 & 19.29 & 0.00 & 98.00 & $<0.01$ \\
\hline
\end{tabular}

SD: Standard deviation; NS: Not significant; RT: Renal transplantation; PI: Plaque index; GI: Gingival index; PPD: Probing pocket depth; PBI: Papilla bleeding index; GO: Gingival overgrowth

Table 3: The characteristics of individuals with and without $\mathrm{GO}$ in CsA group

\begin{tabular}{|c|c|c|c|c|c|c|c|c|c|}
\hline & \multicolumn{4}{|c|}{ CsAGO(-) } & \multicolumn{4}{|c|}{$\operatorname{CsAGO}(+)$} & \multirow[b]{2}{*}{$p$-value } \\
\hline & Mean & $S D$ & Min. & Max. & Mean & $S D$ & Min. & Max. & \\
\hline Age & 38.74 & 10.47 & 20 & 68 & 40.80 & 6.40 & 31 & 54 & NS \\
\hline Weight (kg) & 68.24 & 13.34 & 44 & 98 & 74.10 & 10.61 & 53 & 92 & NS \\
\hline Months of after RT & 76.48 & 40.07 & 18 & 221 & 67.20 & 26.82 & 21 & 108 & NS \\
\hline $\begin{array}{l}\text { Serum creatinine concentration } \\
(\mathrm{mg} / \mathrm{dl})\end{array}$ & 1.40 & 0.48 & 0.80 & 2.90 & 1.37 & 0.59 & 0.60 & 2.50 & NS \\
\hline $\mathrm{PI}$ & 1.11 & 0.61 & 0.10 & 3.00 & 2.41 & 0.54 & 1.66 & 3.00 & $<0.01$ \\
\hline GI & 0.70 & 0.47 & 0.11 & 2.22 & 1.75 & 0.93 & 0.27 & 3.00 & $<0.01$ \\
\hline PPD & 2.20 & 0.60 & 0.22 & 4.31 & 4.06 & 0.74 & 2.85 & 5.18 & $<0.01$ \\
\hline PBI & 0.45 & 0.40 & 0.00 & 1.90 & 1.49 & 0.84 & 0.70 & 3.00 & $<0.01$ \\
\hline $\begin{array}{l}\text { Daily dosage of glucocorticoid } \\
\text { (mg/day) }\end{array}$ & 5.85 & 1.93 & 5.00 & 15.00 & 4.90 & 0.31 & 4 & 5 & $<0.05$ \\
\hline Daily dosage of CsA (mg/day) & 141.50 & 42.13 & 50 & 200 & 167.50 & 28.98 & 150 & 225 & NS \\
\hline Blood CsA level (ng/ml) & 636.76 & 124.5 & 258 & 895 & 636.70 & 196.6 & 384 & 952 & NS \\
\hline CsA mg/kg/gün & 0.54 & 0.29 & 0.25 & 1.68 & 0.45 & 0.1 & 0.29 & 0.61 & NS \\
\hline $\mathrm{GO}(\%)$ & 5.08 & 7.01 & 0.00 & 24 & 48.80 & 20.04 & 31.00 & 98.00 & $<0.001$ \\
\hline
\end{tabular}

SD: Standard deviation; NS: Not significant; RT: Renal transplantation; PI: Plaque index; GI: Gingival index; PPD: Probing pocket depth; PBI: Papilla bleeding index; GO: Gingival overgrowth

Demographic, pharmacological and periodontal variables of subjects in the total sample, divided according to the presence/absence of GO, are detailed in Table 2. The length of time after transplantation was longer and statistically significant in CsA using group than TcR using group $(\mathrm{p}<0.001)$. CsA group presented statistically significant all periodontal variables and higher PI $(\mathrm{p}<0.05)$, higher GI $(\mathrm{p}<0.001)$, higher PPD $(\mathrm{p}<0.05)$, higher PBI $(\mathrm{p}<0.05)$ and it was observed that the mean GOI was significantly higher in the CsA group than in the TcR group $(\mathrm{p}<0.01)$.

A shown in Table 3, the characteristics of individuals with and without GO in CsA group. The number of patients in the CsA group with $\mathrm{GO}\left(\mathrm{CsAGO}^{+}\right)$was 10 and number of patients in the CsA group without GO $\left(\mathrm{CsAGO}^{-}\right)$was 50.
When assessing the period throughout time, no significant alteration was observed and mean daily dosage of CsA higher in $\mathrm{CsAGO}^{+}$group but this difference is no significant. In addition, CsA blood levels were also similar in both groups. Daily dosage of glucocorticoid was significantly higher in $\mathrm{CsAGO}^{-}$group $(\mathrm{p}<0.05)$. All periodontal values (PI, GI, PPD, PBI) were significantly higher in $\mathrm{CsAGO}^{+}$group $(\mathrm{p}<0.01)$ and it was observed that the mean GOI was significantly higher also $(\mathrm{p}<0.001)$.

\section{DISCUSSION}

A large portion of transplant subjects that take immunosuppressive drugs present significant functional, esthetic, and phonetic problems due to GO. Gingival overgrowth, for many reasons, depending on the immunosuppressant (CsA, TcR, etc.), calcium channel blockers (nifedipine) and 
anticonvulsants (phenytoin) drugs occur as unwanted side effects.

When GO was evaluated within specific drug regimens, different authors reported higher prevalence rates for subjects medicated with CsA when compared with those medicated with TcR., ${ }^{71,19,20}$ Indeed, prevalence rates of $\mathrm{GO}$ within CsA regimens have been reported to vary in the literature from 15 to $80 \%{ }^{13,20-22}$ and within TcR regimens from 0 to $30 \% .{ }^{7,13,14}$ Spolidorio et $\mathrm{al}^{23}$ including those individuals with renal transplant who were using the $88 \mathrm{CsA}$ and 67 Tac were not find gingival enlargement using TcR patients. Findings from the present study also demonstrated a higher occurrence of GO among subjects under CsA regimens when compared with TcR. When evaluating the occurrence of GO among subjects medicated with TcR, the present study showed a lower occurrence of GO when comparing with CsA. This occurrence was similar to other studies. ${ }^{24,25}$

Various studies ${ }^{16,23-25}$ showed that the concomitant use of CsA and calcium channel blockers could produce a synergistic effect on GO in subjects taking these drugs. For this reason, we chose to exclude calcium channel blockers from the present study. To the best of our knowledge, a few studies have previously compared the GO in recipients with RT who used CsA or TcR in the absence of calcium channel blockers. First article ${ }^{25}$ that evaluates and compares GO in recipients with RT who used CsA or TcR in the absence of calcium channel blockers showed that the GO mean was significantly lower in the TcR group than in the CsA group 180 days after transplantation. In this study, the TcR group showed a mean GO of $2.55 \%$ and the CsA group showed a mean of $12.36 \%$ after receiving RT $(\mathrm{p}<0.01)$. In CsA group if the GO considered significant the percentage would be 16.7. Gingival overgrowth was not observed significantly in TcR group. The results of this study are similar to those obtained in the study by Paixão et $\mathrm{al}^{25}$ who observed a mean GO of $5.4 \%$ for the CsA group and $17.4 \%$ for the TcR group.

The GO cases caused by the use of drugs are observed in the anterior teeth in general, and in the labial surfaces in particular. As the overgrowth that initially holds the interdental area advances, this can expand on to the gingivial area and the margins of the gum..$^{21,26,27}$ For this reason, in order to identify GO more accurately, and in order to not ignore the aspect of 'GO that has clinical implications' that needs surgical intervention, we have observed and evaluated on the lower and higher anterior teeth of our case studies. There is a range of indexing systems available that considers observations about GO. In our study, we chose to adopt the methodological approach introduced by Seymour et $\mathrm{al}^{18}$ to identify issues with $\mathrm{GO}$, as this is the most acknowledged and commonly used clinical method. In addition, we refer to $\geq 30$ as the 'GO that has clinical implications' in order to evaluate on the GO which needs surgery. 10,28

There are two pieces of research which focus on identifying the effect of time after RT on the GO. ${ }^{24,25}$ In our study, we have observed our patients once only and it was on the condition that it as at least 3 months after the RT. In the CsA group, the approximate time is 74.93 months and in the TcR, it is 32.30. By comparing the time, the RT statistical differences have been found to be $(\mathrm{p}<0.001)$. The reason behind the increase in the GO within the CsA (compared to TcR) might be related to this statistical difference. However, the relationship between $\mathrm{GO}$ and the amount of time spent in using drugs do not signal a connection between the two. ${ }^{7,13}$ In most cases, GO occurs between first and third month, and the longer time it takes, the slower GO occurs. In this regard, our study concurs with the results of other studies that prove that there are not any statistical links between $\mathrm{CsAGO}^{+}$ and $\mathrm{CsAGO}^{-29-31}$

This study recorded the amount of immunosuppressants used by each individual on a daily basis. However, because the main immunosuppresants are different, we were not able to provide a comparative analysis between the patient groups who use Tac and CsA. Those patients in the group which used CsA, there was no difference between the $\mathrm{CsAGO}^{+}$and $\mathrm{CsAGO}^{-}$groups in terms of the daily dose of drugs. In considering the possible correlation between the patient's body weight, the dose used, and the GO we have compared the CsA doses per kilogram between the $\mathrm{CsAGO}^{+}$and $\mathrm{CsAGO}^{-}$groups; however, no differences were observed. Also, there were no differences as to blood levels between the two groups. This may be a result of the different numbers of patients in each group.

Previous research has demonstrated that azathioprine has anti-inflammatory qualities, and that in cases of immunosuppressive curing protocols, if used adjacent to CsA use, it requires a much lower CsA dose. ${ }^{11,32}$ Seymour et $\mathrm{al}^{33}$ compared two groups made up of 24 patients with renal transplants who use CsA and azatioprin, and found out that it does not have unwanted side effects on the periodontal tissues. In those patients who used azthioprine or prednizon, a lower level of CsA dose and CsA blood level has been identified. Wilson et $\mathrm{al}^{34}$ and Thomason et $\mathrm{al}^{32}$ identified a opposite correlation between azathioprine and prednizon doses and GO. Similarly, in our study, in the CsAGO ${ }^{+}$group, approximately daily levels of glucocorticoid was 4.90. In those in the $\mathrm{CsAGO}^{-}$the level was 5.85 (mg/day). This is meaningful statistically $(\mathrm{p}<0.05)$.

An other study showed that plaque with CsA and stimulated salivary flow was reserve for the release of CsA. ${ }^{35}$ Hallmon and Rossmann, ${ }^{36}$ concluded that the 
existence of plaque increases GO. Our research found a significant difference between CsA and TcR groups in regard to plaque index. In the TcR group, the approximate score for plaque index is $0.98 \pm 0.63$, and in the CsA group it is $1.33 \pm 0.77$. There are a number of studies in literature that concurs with our findings. It has been confirmed by studies that in the cases of GO that are caused by CsA the bacterial plaque formation is important and good dental hygiene may reduce GO and even be prevented this way. ${ }^{10-12,31,37-39}$ Our findings demonstrate that there is a link between GO and plaque formation. While comparing $\mathrm{CsAGO}^{+}$and $\mathrm{CsAGO}^{-}$groups, it is established that the $\mathrm{CsAGO}^{+}$group has higher levels of plaque index $(p<0.01)$. It must be remembered that GO makes plaque retantion easier.

Gingival index values in the group that uses CsA are understandbly and statistically much higher than the group that used TcR $(p<0.001)$. In those patients who use CsA, the approximate GI rate is $1,87 \pm 0,68$; and in those who use TcR it is $0.47 \pm 0.38$. There are previous studies which concur with our finding. ${ }^{30,31,40}$ However, stating that there are studies availiable showing no signi-ficant difference in GI. ${ }^{33,41}$ In our study group of patient who are using CsA were examined, and found out that the gingival index scores in $\mathrm{CsAGO}^{+}$was significantly higher compare to $\mathrm{CsAGO}^{-}(\mathrm{p}<0.01)$ according to these result, we can say that there is increase in value of GO and GI.

In our study, gingival enlargement was first observed in papillary regions of inflammation in the measure that we use to papillary bleeding index scores, in terms of CsA and TcR of the patient groups statistically significant difference was observed $(\mathrm{p}<0.05)$. Papilla bleeding index average in CsA group was 0.62; but in TcR was recorded as 0.36 . When we evaluate the CsA group, while the mean value in $\mathrm{CsAGO}^{-}$group is $0.45 ; \mathrm{CsAGO}^{+}$is consider to be 1.49 and in which the difference between groups was statistically significant $(\mathrm{p}<0.01)$. Similarly, Costa et $\mathrm{al}^{13}$ revealed in their research that in both CsA and TcR using patients, there is a relationship between the power of GO and PBI. Our research argues that there is a positive link between GO and inflammation.

Increased pocket depth is found to be corrlated to GO when both CsA and TcR using group is compared to each other and CsA group. This is an expected result regarding GO and coronaly positioning of marginal gingiva and formation of pseudopocket. ${ }^{41,42}$

\section{CONCLUSION}

The results of our study show that GO does not occur in patients medicated with TcR, even if TcR shares the same mechanism with CsA. We think that TcR is a good choice for patients suffering from GO if a change about drug regimen is considered.

In order to evaluate and compare the long-term activity of $T c R$, we need to have a research that examines a much longer period of drug use.

\section{CLINICAL RELEVANCE}

- Scientific rationale for the study: Tacrolimus is a recent immunosuppressive agent. Few data regarding the incidence of GO associated with the use of TcR in the absence of calcium channel blockers are available in the literature.

- Principal findings: The severity of GO associated with the use of TcR was significantly lower than that induced by cyclosporine A. Significant difference in the incidence of clinically significant GO was observed between groups.

- Practical implications: Tacrolimus seems to be a good alternative, with respect to the oral condition, for transplant recipients who require immunosuppressive therapy. Dentistry is varying with induction of modern science to practice dentistry. ${ }^{43}$

\section{REFERENCES}

1. Calne RY, Rolles K, White DJ, et al. Cyclosporin-A in clinical organ grafting. Transplant Proc 1981 Mar;13(1 Pt 1):349-358.

2. Tyldesley WR, Rotter E. Gingival hyperplasia induced by cyclosporin-A. Br Dent 1984;157(9):305-309.

3. Starzl TE, Fung J, Jordan M, et al. Kidney transplantation under FK 506. JAMA 1990;264(1):63-67.

4. Rateitschak-Plüss EM, Hefti A, Lörtscher R, Thiel G. Initial observation that cyclosporin-A induces gingival enlargement in man. J Clin Periodontol 1983;10(3):237-246.

5. Greenberg KV, Armitage GC, Shiboski CH. Gingival enlargement among renal transplant recipients in the era of new-generation immunosuppressants. J Periodontol 2008;79(3):453-460.

6. James JA, Jamal S, Hull PS, et al. Tacrolimus is not associated with gingival overgrowth in renal transplant patients. J Clin Periodontol 2001;28(9):848-852.

7. Ellis JS, Seymour RA, Taylor JJ, Thomason JM. Prevalence of gingival overgrowth in transplant patients immunosuppressed with tacrolimus. J Clin Periodontol 2004;31(2):126-131.

8. Adams CK, Famili P. A study of the effects of the drug FK 506 on gingival tissues. Transplant Proc 1991;23(6):3193-3194.

9. Sekiguchi RT, Paixão CG, Saraiva L, Romito GA, Pannuti $\mathrm{CM}$, Lotufo RF. Incidence of tacrolimus-induced gingival overgrowth in the absence of calcium channel blockers: A short-term study. J Clin Periodontol 2007;34(7):545-550.

10. Thomason JM, Seymour RA, Rice N. The prevalence and severity of cyclosporin and nifedipine-induced gingival overgrowth. J Clin Periodontol 1993;20(1):37-40.

11. Somacarrera ML, Hernández G, Acero J, Moskow BS. Factors related to the incidence and severity of cyclosporin-induced gingival overgrowth in transplant patients. A longitudinal study. J Periodontol 1994;65(7):671-675. 
12. Thomason JM, Kelly PJ, Seymour RA. The distribution of gingival overgrowth in organ transplant patients. J Clin Periodontol 1996;23(4):367-371.

13. Costa FO, Ferreira SD, Cota LOM, Costa JE, Aguiar MA. Prevalence, severity, and risk variables associated with gingival overgrowth in renal transplant subjects treated under tacrolimus or cyclosporine regimens. Journal of Periodontology 2006;77(6):969-975.

14. Cezário ES, Cota LOM, Ferreira SD, Siqueira FM, Soares RV, Zenóbio EG, Coasta FO. Gingival overgrowth in renal transplant subjects medicated with tacrolimus in the absence of calcium channel blockers. Transplantation 2008;85(2): 232-236.

15. Saxer UP, Muhlemann HR. Motivation and education (in German). SSO Schweiz Monatsschr Zahnheilkd 1975;85(9): 905-919.

16. Silness J, Loe H. Periodontal disease in pregnancy. II. Correlation between oral hygiene and periodontal condition. Acta Odontol Scand 1964;22:121-135.

17. Löe H, Lilness J. Periodontal disease in pregnancy. I. Prevalence and severity. Acta Odontol Scand 1963;21:533-551.

18. Seymour RA, Smith DG, Turnbull DN. The effects of phenytoin and sodium valproate on the periodontal health of adult epileptic patients. J Clin Periodontol 1985;12(6):413-419.

19. Gong YM, Cao LF, Ynag Y, Gu ZY. Relationship of putative periodontopathogenic bacteria and drug-induced gingival overgrowth. Zhonghua Kou Qiang Yi Xue Za Zhi 2008a;43(6): 347-351.

20. Lima RB, Benini V, Sens YA. Gingival overgrowth in renal transplant recipients: a study concerning prevalence, severity, periodontal, and predisposing factors. Transplantation Proceedings 2008;40(5):1425-1428.

21. American Academy of Periodontology (AAP). Drugassociated gingival enlargement. Journal of Periodontology 2004;75(10):1424-1431.

22. Greenberg KV, Armitage GC, Shiboski CH. Gingival enlargement among renal transplant recipients in the era of new-generation immunossupressants. Journal of Periodontology 2008;79(3):453-460.

23. Spolidorio LC, Spolidorio DMP, Massucato SEM, Neppelenbroek KH, Campanha NH, Sanches MH. Oral health in renal transplant recipients administered cyclosporin A or tacrolimus. Oral Diseases 2006;12(3):309-314.

24. Cota LOM, Aquino DR, Franco GCN, Cortelli JR, Cortelli SC, Costa FO. Gingival overgrowth in subjects under immunosuppressive regimens based on cyclosporine, tacrolimus, or sirolimus. J Clin Periodontol 2010;37(10):894-902.

25. Paixão CG, Sekiguchi RT, Saraiva L, Pannuti CM, Silva HT, Medina-Pestana J, Romito GA. Gingival overgrowth among patients medicated with cyclosporin A and tacrolimus undergoing renal transplantation: a prospective study. J Periodontol 2011 Feb;82(2):251-258.

26. Seymour RA, Heasman PA. Drugs and the periodontium. J Clin Periodontol 1988;15(1):1-16.

27. Dongarı A, McDonnel HT, Langlais RP. Drug induced gingival overgrowth. Oral Surg Oral Med Oral Pathol 1993; 76(4):543-548.
28. Thomason JM, Seymour RA, Ellis J. The periodontal problems and management of the renal transplant patient. Review. Ren Fail 1994;16(6):731-745.

29. Rostock MH, Fry HR, Turner JE. Severe gingival overgrowth associated with cyclosporine therapy. J Periodontol 1986;57(5): 294-299.

30. McGaw T, Lam S, Coates J. Cyclosporin-induced gingival overgrowth: correlation with dental plaque scores, gingivitis scores, and cyclosporin levels in serum and saliva. Oral Surg Oral Med Oral Pathol 1987;64(3):293-297.

31. Pernu HE, Pernu LMH, Huttunen KRH, Nieminen PA, Knuuttila, MLE. Gingival overgrowth among renal transplant recipients related to immunosuppressive medication and possible local background factors. . Periodontol 1992;63(6): 548-553.

32. Thomason JM, Seymour RA, Ellis JS. Risk factors for gingival overgrowth in patients medicated with ciclosporin in the absence of calcium channel blockers. J Clin Periodontol 2005; 32(3):273-279.

33. Seymour RA, Smith DG, Rogers SR. The comparative effects of azathioprine and cyclosporin on some gingival health parameters of renal transplant patients: A longitudinal study. J Clin Periodontol 1987;14(10):610-613.

34. Wilson RF. Morel A, Smith D, Koffman CG, Ogg CS, Rigden SP, Ashley FP. Contribution of individual drugs to gingival overgrowth in adult and juvenile renal transplant patients treated with multiple therapy. J Clin Periodontol 1998;25(6): 457-464.

35. Seymour RA, Thomason JM, Ellis JS. The pathogenesis of drug-induced gingival overgrowth. J Clin Periodontol 1996; 23(3 Pt 1):165-175.

36. Hallmon WW, Rossmann JA. The role of drugs in the pathogenesis of gingival overgrowth. A collective review of current concepts. Review. Periodontol 2000Oct, 1999;21:176-196.

37. Thomason JM, Seymour RA, Ellis JS, Kelly PJ, Parry G, Dark J, Ilde JR. Iatrogenic gingival overgrowth in cardiac transplantation. Journal of Periodontology 1995;66(8):742-746.

38. King GN, Fullinfaw R, Higgins TS, Walker RJ, Francis DMA, Wiesenfeld D. Gingival hyperplasia in renal allograft recipients receiving cyclosporin-A and calcium antagonists. J Clin Periodontol 1993;20(4):286-293.

39. Ellis JS, Seymour RA, Steele JG, Robertson P, Butler TJ, Thomason JM. Prevalance of gingival overgrowth induced by calcium channel blockers, a community-based study. J Periodontol 1999;70(1):63-67.

40. Daley TD, Wysocki GP, Day C. Clinical and pharmacologic correlations in cyclosporine induced gingival hyperplasia. Oral Surg Oral Med Oral Pathol 1986;62(4):417-421.

41. Afonso M, Bello VO, Shipli JA, Sposto MR. Cyclosporine-A induced gingival overgrowth in renal transplant patients. J Periodontol 2003;74(1):51-56.

42. Margiotta V, Pizzo I, Pizzo G, Barbaro A. Cyclosporin and nifedipine-induced gingival overgrowth in renal transplant patients: correlations with periodontal and pharmacological parameters, and HLA-antigens. J Oral Pathol Med 1996;25(3): 128-134.

43. Saini R. Ozone therapy in dentistry: a strategic review. J Nat Sc Biol Med 2011;2(2):151-153. 